\title{
1. A portable philosophy toolkit for the Anthropocene
}

\author{
Carlos Jesús García-Meza
}

\section{INTRODUCTION: PHILOSOPHY AND THE ANTHROPOCENE}

The incontestable evidence of the Anthropocene and its portentous horizon of risk and uncertainty has led some thinkers in the social sciences and the humanities to explore and challenge the main philosophical assumptions of modernity (still affecting our contemporaneity), that is, how we think about ourselves as a living species and how we define our relation to the natural world and the world at large. Importantly, these are not just theoretical questions, but they crucially determine how we live and act (and therefore they also have to do with our future). These kinds of questions are formally dealt with by three branches of philosophy: ontology, epistemology, and ethics. Ontology is the study of existence, reality, and becoming, and tries to give answers to the primordial question of what the world is made of. Epistemology studies the nature, sources and validity of knowledge, and is oriented to the question of how reality or the world can be known (related to this, methodology deals with the methods that give access to or constitute that knowledge). Finally, ethics studies the good, the right and the valuable.

In mainstream philosophy - and thus in the social sciences and the humanities - ontology, epistemology and ethics share in two fundamental assumptions, both with a historical origin in the Enlightenment: anthropocentrism and human exceptionalism. First, anthropocentrism is the privileging of the human being against other living beings (and more so against the many entities that populate the world, be they organic, inorganic, or inert). The idea is that human beings are the most important entities in the world, so everything is interpreted and justified in terms of human values and experience. This (self-attributed) supremacy of the human establishes a neat separation between humanity and the rest of the world; in other words, a first binary distinction (humans/ nonhumans) is created, out of which many other dual dichotomies have arisen: society/nature, mind/body (the classical Cartesian dualism), subject/object, 
and the like. Again, this basic distinction between human and nonhuman (or nature) rests on an ontological assumption: the world is composed of humans and nature, but humans are different, superior, better, than nature.

Second, if the prevalent ontology underpins a dualistic outlook to the world in which we humans see ourselves as separate from nature, then it may also lead us to assume that we are entitled to do things to nature (e.g., extracting resources and destroying ecosystems, polluting air and water, warming the atmosphere), without necessarily having any ethical sense of responsibility or guilt about it. In other words, the first ontological assumption (anthropocentrism) is accompanied by another one, human exceptionalism, in which the (human) prerogative of agency, defined as the capacity to act and effect changes on the world, is considered an attribute pertaining only to humans.

If these two ontological assumptions are taken for granted (consciously or not) then it follows that the concomitant epistemological and ethical thinking and actions will maintain the same logic of anthropocentrism and human exceptionalism. But what the Anthropocene has made very clear is that, paradoxically, the practical consequences of these two assumptions have had increasingly disastrous effects not only on other living beings (and nonliving entities) but also on us. What is needed is a different trifecta of ontology, epistemology and ethics that instead of holding itself to a logic of ontological separation and superiority (and the associated violence to other beings and entities and even to ourselves), may recognize the interdependence of the human with the rest of the world. Let us call this new ontological reconfiguration a "more-than-human" world (Whatmore, 2006), an ontological shift that may well allow us to acknowledge our ontological entanglement(s) in more-than-human realities that can relocate us in new, symbiotic, biophilic relationships with the planet, instead of the usual ones of separation, parasitism and destruction.

Before we enter into the philosophical terrain of the new materialisms, a general denomination to the ontology of a more-than-human world, a brief note on the title of this chapter. In contemporary academic spheres, theories and concepts are usually understood as "tools," that is, things that may help us to get a better understanding of a given topic. In this sense, this chapter offers a minimal set of tools, that is, a "portable toolkit" for readers who wish to take a first, non-professional neomaterialist philosophical look at the Anthropocene. For didactic sake, philosophical "tools" are italicized words in this chapter.

\section{THE NEW MATERIALISMS}

New materialisms are a variegated set of theories representing a branch of the so-called ontological turn that has been happening in theorization and 
empirical studies in contemporary social sciences and humanities since the mid-1990s. Inaugurating this philosophical perspective, Manuel DeLanda defined a neomaterialist approach as

a philosophical stance which rejects ideas of progress not only in human history but in natural history as well. Living creatures, according to this stance, are in no way 'better' than rocks. Indeed, in a nonlinear world in which the same basic processes of self-organization take place in the mineral, organic and cultural spheres, perhaps rocks hold some of the keys to understand sedimentary humanity, igneous humanity and all their mixtures. (DeLanda, 1996)

After DeLanda, in 2000 Rosi Braidotti used the term of "new materialism" as well (Braidotti, 2000, p. 160).

The new materialisms comprise a transdisciplinary group of authors and theories which include, amongst the most noteworthy, Bruno Latour (actor-network theory, or ANT), Manuel DeLanda (assemblage theory), Karen Barad (agential realism), Jane Bennett (vitalist materialism), Rosi Braidotti (posthumanism), Graham Harman (object-oriented ontology), and Timothy Morton (hyperobjects theory). New materialisms are also associated with other theoretical perspectives such as process philosophy, affect theories, and non-representational theories (Coole and Frost, 2010; Depelteau, 2018; Fox and Alldred, 2017). All these theories and perspectives are very much indebted to feminist thinking, which infuses new materialisms' orientation to embodiment (human and nonhuman bodies), materiality, affect and emotions, as well as the acknowledgment of the importance of situatedness and relationality.

Each neomaterialist author has developed her or his own approach to the literature of the new materialisms, so relative divergences exist between them, but nonetheless all of them share in some basic tenets, related to the following themes of materiality, agency, and relationality.

\section{THREE TENETS OF THE NEW MATERIALISMS}

\section{Materiality}

Taking an ontological turn to matter, new materialisms put emphasis on the materiality of the world. Living and nonliving beings, material stuff of any kind, places and spaces (urban, architectural, natural, etc.), material forces (of water, or air, etc.), and even non-physical things (memories, ideas, thoughts, feelings, or imaginary and fantastic elaborations), are all considered as matter, in the sense of having the capacity to produce effects or changes in the world (therefore a capacity for worlding, i.e., the creation of new "worlds").

Traditionally, philosophy and the natural sciences have treated matter as something that is dumb, static, and inert: a passive stuff subjected to an exter- 
nal and active human dominion and control. Opposing this view, new materialisms claim that the whole field of matter (existence itself, including human and nonhuman entities) is "alive" and full of creativity, and has the capacity to produce effects and form new and complex entities. Microplastics, e-waste, pollutants, carbon molecules, electrical batteries, or "smart" textiles all have a real and highly visible efficacy that goes well beyond their descriptions (ontology) as scientific or technological products, commodities, or discourse (i.e., referents to pieces of information or of laws and regulations, or parts of our conversations). Instead of reducing the materiality of the world to culture and discourse, an analytical mode that conceals and disregards that very materiality rendering it trivial, new materialisms force us to think beyond discursive representations and ask us to recognize the very materiality of the world.

Contrary to what the natural sciences claim, matter for new materialisms is rather boundless, unpredictable and uncontrollable. Thus, for example, new materialisms reject the notion of nature as the background for human endeavors, in which "natural" matter is seen as passively waiting for humans to grant it meaning (for example, as a reserve of "natural" resources for exploitation, or as a business target for geo-engineering projects). New materialisms strongly reject this "bifurcation of nature" (Whitehead, 1929), the foundational division of the world into reciprocally exclusive categories (general/particular, mind/matter, science/philosophy, etc.), each struggling for winning over the other. Whitehead warns us to consider the loss we may experience if we follow this "bifurcation of nature." As he says, it is nonsensical attempting to ontologically determine what belongs to nature and what belongs merely to our (human) experience: "For us the red glow of the sunset should be as much a part of nature as are the molecules and electric waves by which men of science would explain the phenomenon" (Whitehead, 1929, p. 29). Thus, Whitehead rejects the dualistic thinking of decoupling nature (living entities, landscapes, things) from human culture (society, communication, language). Neomaterialist thinkers assert that this dualism is false, being a distinction that results, for instance, from analytical or research practices that work by tracing arbitrary boundaries between what counts (by analysts or researchers) as cultural and what as natural. What we actually have is, for instance, in Donna Haraway's coinage, natureculture, in which "all the actors become who they are in the dance of relating, not from scratch, not ex nihilo, but full of the patterns of their sometimes-joined, sometimes-separate heritages both before and lateral to this encounter" (Haraway, 2008, p. 25).

Regarding matter as active and productive leads to a "flat ontology" (DeLanda, 2006), which means that all entities in the world have the same ontological status. This implies that there is no ontological reason to defend and retain the many binary distinctions that frame and determine our accustomed outlook to the world: culture/nature, human/nonhuman, urban/rural, 
structure/agency, global/local, animate/inanimate, organic/inorganic, sentient/ non-sentient, alive/inert, life/death, mind/matter, subject/object, language/ matter, original/copy, abstract/concrete, representation/reality, base/superstructure, micro/macro, and so on. Given the materiality of the world, new materialisms operate outside of or beyond these dualisms. This does not mean that the components of each pair of opposites do not exist, are useless, or are not taken into account anymore. It is simply that the way of considering them is more in terms of inclusion and mutual implication, not of an a priori separation, autonomy, and the privileging of one term in a pair. Besides, the problem with this binary logic is that the stuff making up reality is considered either natural or social, active or passive, agent or acted upon, and so on, without allowing for the possibility to see reality as populated by, in Bruno Latour's term, hybrids, entities that do not quite readily belong to one or the other side of a given binary distinction. Examples of hybrids are corporations, the ozone layer, frozen embryos, digital surveillance systems, genetically modified organisms, or the COVID-19 pandemic.

One of the most interesting and original articulations of (neo)materiality is Timothy Morton's concept of hyperobjects (Morton, 2013). A hyperobject is a vast and complex entity dispersed in space and in time. Global warming, radioactive particles, Styrofoam consumables, radioactive particles, plastic articles, and fine dust, are examples of hyperobjects. According to Morton (2013, pp. 27-95), hyperobjects have five properties. (1) Hyperobjects are viscous: they stick to us despite our efforts to isolate and categorize them. The more one tries to study and know them, the stranger they become (they are, Morton says, strange strangers), and the more one tries to externalize and classify them, the more one finds oneself entangled in them. (2) Hyperobjects are non-local: they are indeterminately dispersed. (3) Hyperobjects are temporally undulated: they encompass multiple temporalities and rhythms, and they will far outlive us. (4) Hyperobjects are phased: one can only ever see a portion of them, as it is impossible for us to see them as a whole. (5) Hyperobjects are interobjective: they form a mesh, a heterogeneous assemblage of humans and nonhumans. Morton's characterization of hyperobjects as "strange strangers" means that they are completely out of reach to our limited intelligibility of the world in terms of bounded entities such as "nature" or "society."

Morton's concept of hyperobjects derives from object-oriented ontology, or OOO (Harman, 2017), another philosophical strand of the ontological turn that posits objects (instead of actors or actants) as the only components of the world. Basically, OOO deals with two philosophical concepts: finitude and withdrawal. Finitude is our failure to know or access objects and reality itself, since an inescapable ontological gap between things and appearances pervades the world. Withdrawal means that objects cannot be grasped by any means at all, since they always withdraw or stay separated from other objects (as 
humans, for instance), even from themselves. OOO assumes a realist view of the world (i.e., the world exists outside our minds), so objects (or hyperobjects) can only be known metaphorically, by allusive or vicarious means (Harman 2016, p. 17). This represents a great challenge to the endeavor of knowledge in the Anthropocene, that is, the epistemic efforts we have to make in order to come to grips with the radically new hyperobjects with which we cohabit now and in the future.

\section{Agency}

If the concept of agency is an exclusive human trait for mainstream social sciences and humanities, new materialisms challenge this assumption and extend the capacity to act to all the entities of the world, so it is no longer the case that only humans act upon nonhuman matter, which then it passively reacts. Plants, microbes, winds, rocks, rivers, or wearable apps do not simply react to or obey our actions; they have their own ways of acting. Nonhuman things can actually make us act much in the same way as they can respond to our actions; they have, as we do, a capacity to affect and be affected. Or as Jane Bennett (2010) puts it, things have thing-power. Entities have an agentic capability much like the bottle's label in Alice in Wonderland saying, "Drink me." For Bennett, matter is vibrant, that is, it is always changing and in a constant process of fluidity, and it also has the capacity of acting in the world (i.e., agency). Bennett defines vitality as "the capacity of things - edibles, commodities, storms, metals - not only to impede or block the will and designs of humans but also to act as quasi agents or forces with trajectories, propensities, or tendencies of their own" (Bennett, 2010, p. viii). In this same vein, and refusing anthropocentrism too, DeLanda (2006) claims that matter has its own morphogenetic capacities, rather than being just passive stuff at the mercy of humans. An interesting empirical case of this is Bennett's assemblage analysis of how an electricity blackout in the United States in 2003 was produced by many heterogeneous intertwined actants, including "coal, sweat, electromagnetic fields, computer programs, electron streams, profit motives, heat, lifestyles, nuclear fuel, plastic, fantasies of mastery, static, legislation, water, economic theory, wire and wood" (Bennett 2010, p. 25).

Defining herself as a "compostist," Donna Haraway uses the compost metaphor to describe the vast variety of human and nonhuman entities that happen to gather together in collectives and their capacity to generate vitalities (Haraway, 2016). This adds a second layer of meaning to the expression of "flat ontology": agency is distributed among all entities, so the world is continuously emerging and created in the form of entangled events.

Now, the concept of (human) agency is usually associated with (human) intentionality, so the category of "actor" or actant is reserved to human beings. 
As a way to avert this traditional association, new materialisms have developed an alternate conceptualization. For instance, actor-network theory uses the term actant, which is also used by Bennett (2010); an actant is something that acts, brings about events, or generates effects in the world. Street bumps, chemical compounds, surplus behavioral data, $\mathrm{CO}_{2}$, coltan, or African slave kids are all actants. The important point is that instead of thinking of each actant as a particular agent that can act on its own (i.e., having agency in itself), new materialisms claim that agency is not a property of individual actants, but is located in the interrelationships of actants. Assuming that nonhuman entities are agentic consequently causes the dissolution of the association of agency with intentionality. Even if we may still believe that we have and can exert our intentions, the myriad of actions of nonhuman actants will interfere with our own actions, so the final result of all those actions ("ours" and "theirs") cannot be easily determined in advance, nor can authorships be readily assigned to particular actants.

For ANT, the list of who or what constitutes an actor is, in the first place, undefined, and can include "human beings, machines, animals, 'nature', ideas, organizations, inequalities, scale and size" (Law, 2009, p. 141). Latour says that an actant "can literally be anything provided it is granted to be the source of action" (Latour, 1996, p. 373). More technically, the term actant (or actor) is any entity that can make other entities act, and thus "does modify a state of affairs by making a difference" (Latour, 2005, p. 71), or as Callon (1986; 1991) puts it, an actant produces associations between heterogeneous entities, be they tools, ideas, waste, policies, human skills or buildings. These associations can exist not only on a "local" level but can also extend in time and space (Latour, 2005).

As agency is distributed, individual actors never "act" by themselves, since action (agency) is enacted by the differences and connections made between actors. In methodological terms, this is called the principle of symmetry, which prescribes an equal (i.e., ontological) treatment to all actors. To avoid misunderstandings, a point of clarification is given by actor-network theorist John Law: "to say that there is no fundamental difference between people and objects is an analytical stance, not an ethical position" (Law, 1992, p. 383). The symmetrical treatment of human and nonhuman actors is then used to analyze how actor-networks are formed, how connections are stabilized, how actors enter, exit or develop, and how their power-relations shift therein.

Another implication of the "flat ontology" is that human anthropocentrism and exceptionalism are radically challenged. As mentioned, traditional ontology posits humans as exceptional. Whereas (common) matter is depicted as passive, predictable, and controllable, humans instead are imagined as active, rational, unpredictable and possessing agency. Presumably, humans have the capacity to effect changes in the world according to their will and intentions. 
But if, as new materialisms claim, the materiality of the world is not passive, and both humans and nonhuman actions co-mingle with rather unknowable and uncontrollable outcomes, then the issue of "who" is in control is indeterminate. The Anthropocene is just one but crucial case for posing a posthuman agency. The serious and unintended outcomes of our actions on "nature" (anthropogenic events, such as extreme weather, floodings, species extinctions, global warming, glaciers melting, etc.) easily subvert any pretense of human dominion of the planet. This does not mean that it is precisely because of our actions that the world is in peril; it is just that anthropocentrism and human exceptionalism have to be abandoned, now that many biospheric processes are on the course of, perhaps, unprecedented irreversible and disastrous changes.

Disavowing human agency also has ethical and political implications in terms of advancing an "antihumanist" or posthuman stand in the social sciences and the humanities, as it can provide a ground for (a) a critical assessment of humans' negative impact on the environment, and (b) at the same time serve as an entry point to a more biophilic and entangled relationship with the planet itself. For example, the anthropocentric legal system that grants property rights to individuals and corporations could be challenged as it provides the means to the commodification of nature (i.e., culture/nature dualism) and the promotion of a global market-based logic for both human and nonhuman interactions, with evident and increasingly pernicious effects on all of "us": human society and the whole of the biosphere. On the other hand, the concept of posthuman agency can also help us to explore nonhumans' capacities and moral and legal rights previously set aside for humans only. Interesting cases in this direction are, for instance, these posthuman inquires: "Do glaciers listen?" (Cruikshank, 2005), and "How forests think?" (Kohn, 2013), which have a foundational origin in Christopher Stone's book of 1972, Should Trees Have Standing? (see Stone, 2010).

\section{Relationality}

By refusing any dualisms, new materialisms open up the prospect to explore how human and nonhuman entities affect each other and make things happen. A neomaterialist flat ontology allows the rejection of social macrostructures (neoliberalism, sociopolitical hierarchies, patriarchy, the State) as explanatory devices for society and even for nonhuman situations (e.g., natural events). For Latour, researchers "have confused what they should explain with the explanation" (Latour, 2005, p. 8), meaning that the "social" is not a kind of glue that holds social things together but rather is "what is glued together by many other types of connectors" (ibid, p. 5). Society, as nature, then, is not a "specific realm ... but only ... a very peculiar movement of reassociation and reassembling ... a trail of associations between heterogeneous elements" (ibid, p. 5). 
Instead of appealing to systems or structures "out there," new materialisms propose "actor-networks," "phenomena," "naturecultures," or "assemblages" as the real collective enmeshments of human and nonhuman entities that constitute the world. The new materialisms research explores the agential relationships and reciprocities contained within entanglements, and this is done in a transdisciplinary fashion, that is, considering the ad hoc biological, social, geological, historical, aesthetic, physical, and so on, elements at hand, so as to study and depict not the event as a "thing" or state of things but as becoming, looking for the iterative processes of materialization in which the world (the event, phenomenon, etc.) comes about.

Actor-networks, assemblages and the like are emergent materializations which are fluid, unstable, and uncertain. At every moment, these assemblages are endlessly configured and reconfigured by their contacts with other impermanent phenomena. In the course of these events or becomings, the frontiers (their "identities," so to speak) of the participating entities (human and nonhuman) are established and kept for a while; nonetheless, the "separated" entities are transversally connected (Bennett, 2010). Instead of saying that entities have their own causal effects, new materialisms claim that entities should be perceived as becoming with one another.

A corollary of the neomaterialist ontology of relationality is that the world does not depend on transcendent things such as gods, capitalism, spirits, destiny, Gaia, or macrostructures, that is, pre-existing things which surpass, exceed or go beyond down-to-earth, empirical limits; the ontology of new materialisms is rather of finitude and immanence, that is, it exists or remains within the world or reality of materiality. In the language of the agential realism of Karen Barad, since entities are always inside the phenomenon, it is preferable to say that entities encounter each other as intra-action, instead of the customary, dualistic expression of inter-action (Barad, 2007).

\section{CONCLUSION}

The ontological turn, or more broadly, the philosophical shift of the new materialisms invites us to abandon the dualistic and transcendent thinking that permeates the current anthropocentric inquiries in the social sciences and the humanities, by radically rethinking the themes of materiality, agency and relationality from a posthuman framework of finitude and immanence and for a human and nonhuman eco-cohabitation. What implications might exist if we shift our philosophical outlook into a neomaterialist one? First, one directly appropriate to the Anthropocene, insofar as the new materialisms displace the attention to anthropocentrism and human exceptionalism towards posthuman existence in a more-than-human world, thus promoting a more symbiotic and biophilic entanglement with "nature" and the whole of world materiality. 
Second, since for the new materialisms the world is not made of a priori structures and systems, this opens up the possibility for a really creative and productive engaging in events, becomings, and assemblages. And third, a good part of the new materialisms deal with the question of which politics and ethics are best fitted to do research that may help us to better understand the world and how to change it or intervene in it for the better. As Judith Butler says:

We are all, in the very act of social transformation, lay philosophers, presupposing a vision of the world, of what is right, of what is just, of what is abhorrent, of what human action is and can be, of what constitutes the necessary and sufficient conditions of life. (...) But perhaps there is, prior to these questions, all of which are important questions, another question: the question of survival itself. (Butler, 2004, p. 205)

Biological and civilizational survival indeed is in fact what is at stake due to the human existential risk posed by the Anthropocene. New materialisms represent perhaps the adequate philosophical response to this predicament, being its newness that the Anthropocene precisely asks us for, insofar as current and past ontologies of the Holocene (e.g., totemism, animism, analogism and naturalism; see Descola, 2013) are "rendered obsolete" (Hamilton, 2020, p. 116) by the new geological age of the Earth System. New materialisms might as well be a "fifth ontology" (Hamilton, 2020), but, as Hamilton claims, it should necessarily imply an emotional disposition of attunement (see also Morton, 2013) to the dread of the Anthropocene. Of course, attunement, as important and fundamental as it is, is not the only emotion required by the Anthropocene, as the groundbreaking work of Glenn Albrecht on "psychoterratic emotions" has shown (see Albrecht, 2019). A pending research work is the theoretical and empirical exploration of the intermingling of the new materialism's tenets of materiality, agency and relationality with the novel field of psychoterratic emotions if we are to relatively successfully navigate the uncharted waters of the Anthropocene.

\section{REFERENCES}

Albrecht, Glenn. (2019). Earth emotions: new words for a new world. Cornell University Press.

Barad, K. (2007). Meeting the universe halfway: quantum physics and the entanglement of matter and meaning. Duke University Press.

Bennett, J. (2010). Vibrant matter: a political ecology of things. Duke University Press.

Braidotti, R. (2000). Teratologies. In: Ian Buchanan and Claire Colebrook (eds.), Deleuze and feminist theory. Edinburgh University Press, pp. 156-172.

Butler, J. (2004). Undoing gender. Routledge. 
Callon, M. (1986). Some elements of a sociology of translation: domestication of the scallops and the fishermen of St Brieuc Bay. In: J. Law (ed.), Power, action and belief: a new sociology of knowledge? Routledge, pp. 196-223.

Callon, M. (1991). Techno-economic networks and irreversibility. In: J. Law (ed.), A sociology of monsters. Routledge, pp. 132-161.

Coole, D. H. and Frost, S. (2010). New materialisms: ontology, agency, and politics. Duke University Press.

Cruikshank, J. (2005). Do glaciers listen? Local knowledge, colonial encounters, and social imagination. University of British Columbia Press.

DeLanda, M. (1996). The geology of morals. A neo-materialist interpretation. Retrieved from http://www.t0.or.at/delanda/geology.htm.

DeLanda, M. (2006). A new philosophy of society: assemblage theory and social complexity. Continuum.

Depelteau, F. (ed.) (2018). The Palgrave handbook of relational sociology. Palgrave.

Descola, P. (2013). Beyond nature and culture. University of Chicago Press.

Fox, N. J. and Alldred, P. (2017). Sociology and the new materialism: theory, research, action. Sage.

Hamilton, C. (2020). Towards a fifth ontology for the Anthropocene. Angelaki, 25(4), $110-119$.

Haraway, D. J. (2008). When species meet. University of Minnesota Press.

Haraway, D. (2016). Staying with the trouble: making kin in the Chthulucene. Duke University Press.

Harman, G. (2016). Immaterialism: objects and social theory. Polity.

Harman, G. (2017). Object oriented ontology: a new theory of everything. Penguin Random House.

Kohn, E. (2013). How forests think: toward an anthropology beyond the human. University of California Press.

Latour, B. (1996). On actor-network theory: a few clarifications. Soziale Welt, 47, 369-381.

Latour, B. (2005). Reassembling the social: an introduction to actor-network-theory. Oxford University Press.

Law, J. (1992). Notes on the theory of the actor-network: ordering, strategy and heterogeneity. Systems Practice, 5, 379-393.

Law, J. (2009). Actor network theory and material semiotics. In: B. Turner (ed.), The new Blackwell companion to social theory. Wiley-Blackwell, pp. 141-158.

Morton, T. (2013). Hyperobjects: philosophy and ecology after the end of the world. University of Minnesota Press.

Stone, C. D. (2010). Should trees have standing? Law, morality, and the environment. Oxford University Press.

Whatmore, S. (2006). Materialist returns: practising cultural geography in and for a more-than-human world. Cultural Geographies, 13(4), 600-609.

Whitehead, A. N. (1929). Theories of the bifurcation of nature. In: The concept of nature: The Tanner Lectures delivered in Trinity College, November 1919. Cambridge University Press, pp. 26-48. 